\title{
Mimetizar elementos do sistema das artes para discuti-lo?
}

Mimicking elements of the arts' system to discuss it?

Fabio Oliveira Nunes 


\section{Resumo}

Artistas contemporâneos, com o intuito de lançar provocações, jogam com regimes de ambiguidade e alteridade em suas produções para discutir elementos do próprio sistema das artes visuais - a figura do artista, o museu, o jornalismo cultural, etc. Em diálogo, consideram-se os projetos de artistas como Yuri Firmeza (com seu "artista inventado" Souzousareta Geijutsuka) e Bruno Moreschi (com seu projeto ART $B O O K$, onde cria uma enciclopédia de arte com 50 artistas ficcionais concebidos por ele). Neste contexto, a pesquisa envolve o desenvolvimento prático da persona de um "artista tecnológico" - um robô de conversação que se passa por artista atuando ininterruptamente em uma "teleperformance" via Internet - supostamente instaurando uma relação "direta" entre artista e público.

Palavras-chave: Mimetismo; Arte contemporânea; Arte digital.

\section{Abstract}

Contemporary artists, aiming launching provocations, play with ambiguity and alterity in their production to discuss elements of the visual arts' system itself - the figure of the artist, the museum, the cultural journalism, etc. In dialogue, we analyze the projects of artists such as Yuri Firmness (with his "invented artist" Souzousareta Geijutsuka) and Bruno Moreschi (with his project ART BOOK, where he creates an encyclopedia of art with 50 fictional artists designed by him). In this context, the research involves the practical development of the persona of a "technological artist" - a chatbot that pretends to be an artist acting in a "teleperformance" on the Internet supposedly introducing a "direct" relationship between artist and audience.

Keywords: Mimicry; Contemporary art; Digital art.

ISSN: 2175-2346 


\section{Mimetismo}

Nos anos de 1990, século XX, época da descoberta dos artistas sobre as possibilidades da rede Internet para proposições poéticas, emerge o gênero da web arte (ou net art), e surge assim o site ONOS - ON Operating System (1999). Produção do autor deste texto, o trabalho se efetivava a partir da ambiguidade de uma situação: ao acessar o endereço do site, repentinamente um desktop ${ }^{1}$ preenchia toda a tela, passando a imitar - com ícones, janelas e programas falsos - comportamentos e composição da área de trabalho do sistema operacional mais utilizado naquele momento: Microsoft Windows em suas versões 95 e 98 . Assim, com outras incursões artísticas da web ${ }^{2}$, o site possuía claramente a intenção de evidenciar as expectativas do usuário, sua afinidade com o universo digital e, claro, a pertinência entre aquilo que é fatualidade e ficção, tema ainda recorrente não só na experiência de navegação do usuário das redes, mas na dificuldade de validação de cada fato ou imagem com os quais nos deparamos na Internet.

O site denominado ONOS seria antecedido por uma experimentação bem mais conhecida: o célebre site JODI nascido em 1994, dos artistas europeus Joan Heemskerk and Dirk Paesmans. JODI foi uma experiência de heterodoxia aos que defendiam a ideia de que os sites da rede deveriam funcionar com clareza, legibilidade e eficiência. Surpreendendo a muitos, trazia páginas - inclusive na sua abertura - com mensagens de código-fonte, com ícones sem qualquer sentido, imagens e elementos intermitentes e janelas que saltavam sem parar, tudo sem qualquer explicação ao usuário - não havia qualquer texto ou indicação do que realmente se tratava (NUNES, 2010, p.121). Se por um o trabalho suscita "a complexa relação humana com o virtual tecnológico" (DONATI, 1997), por outro é evidente sua similaridade aos comportamentos esperados por vírus de computador - ainda que de fato não seja esse tipo de ameaça.

Há evidentemente um campo bastante profícuo que se situa entre aquilo que assimilamos e a real natureza das coisas. Esse campo produtivo alimenta tudo aquilo que envolve ilusão - e o binômio arte e ilusão é tão recorrente e abrangente, que remota há milênios da existência humana. Ora, no interior da Caverna de Chaveut, França, cerca de 30.000 anos atrás, indivíduos já faziam imagens realistas com a ilusão de movimento de animais - em um "quadro a quadro" possível de ser gerado pela movimentação de suas tochas em chamas. Recuando um pouco menos, encontraríamos o desejo da arte de imitar a natureza - a mimese artística. Se Aristóteles acolhe de Platão a arte como imitação, permite também que ela seja vista como um "embelezamento" ou "melhoramento" da realidade - um novo elemento não contido no mero processo de reprodução (GEBAUER e WULF, 2004, p. 29). Entretanto, se iludir não é novidade na arte, o que estamos a perceber em nossas considerações é a pertinência de uma condição mais específica e sistêmica de ambiguidade e camuflagem: os jogos propostos por ONOS ou por JODI só fazem sentido dentro de uma dinâmica que envolve especialmente um ecossistema propício, só funcionando de fato em determinados contextos, socialmente difundidos. 1. Desktop é o mesmo que "área de trabalho", espaço disponível para abrir
janelas no uso de sistemas operacionais em computadores pessoais.
2. Web refere-se à interface gráfica da rede mundial de computadores - a Internet - em uma simplificação do termo "World Wide Web". 
No livro Mimese na Cultura, os autores Günter Gebauer e Christoph Wulf (2004) definem mimese como "a designação geral para um mundo anterior, real ou somente postulado ou representado, que anuncia um amplo espectro de possíveis referências de um mundo próprio produzido pelo homem" (GEBAUER e WULF, 2004, p. 21). Embora a ideia de mimese esteja intimamente associada à imitação nas artes - sua raiz etimológica, mimos, designa aquele que imita ou representa (ibidem, p. 22) -, os processos miméticos não estão restritos aos trabalhos artísticos; exercem eles um papel fundamental à vida social em suas diferentes esferas. Em diversos momentos, os autores reforçam o caráter relacional da mimese, trazendo os processos baseados neste princípio como fundamentais para o entendimento recíproco nas relações humanas ${ }^{3}$ :

Com a ajuda das capacidades miméticas, percebe-se uma semelhança entre si e o outro, e experimenta-se a percepção de si do outro. Desta forma, chega-se a concordância do agir, das opiniões e dos sentimentos entre os homens. (GEBAUER e WULF, 2004, p.38)

Encontramos os processos de imitação dentro de dinâmicas sistêmicas na natureza sob a denominação de mimetismo. Na biologia, mimetismo é uma relação ecológica em que indivíduos de uma determinada espécie buscam parecer-se com outros organismos, partes ou objetos do meio ambiente em troca de algum benefício, como proteção ou alimento. Denomina-se modelo a espécie que possui alguma característica especial a ser copiada e denomina-se mimética a espécie que, por sua vez, busca assemelhar-se ao modelo ${ }^{4}$. Na natureza, estabelece-se então uma relação entre três elementos: o padrão (modelo), o imitante (espécie mimética) e o receptor do sinal, ou seja, o organismo que pode não encontrar distinção segura entre o padrão e o imitador (BARETT apud GEBAUER e WULF, 2004, p. 40). A adoção do conceito implica a compreensão de que há a instauração de um sistema - termo também originário da biologia, aplicável inclusive aos meios digitais. O termo hoje generalizado para definir conjuntos de partes e elementos interdependentes que formam uma unidade, surge com a Teoria Geral dos Sistemas de Ludwig von Bertalanffy. Esta teoria apresentada ao meio científico em 1947, publicada em 1955, compreendia o sistema como um complexo de elementos em interação e defendia o pensamento sistêmico como contextual (SANTOS e TELLES NETO, 2010).

Dentro destes pressupostos se instaura a pesquisa Mimetismo: Estratégia Relacional em Arte e Tecnologia, na qual se insere este texto, que tem abordado incursões artísticas que visam instaurar sistemas que colocam em xeque o reconhecimento de algo, a partir de dinâmica similar ao que ocorre nos sistemas naturais. Seu objetivo é proporcionar indistinção e ambiguidade entre "verdadeiro" e "falso", dialogando ou atuando em tecnologias digitais. Abordam-se trabalhos artísticos que são intimamente bastante dependentes dos contextos em que atuam, a ponto de sua natureza 3. Também associando relações humanas e mimese, encontramos alguns pensa-
mentos de René Girard, autor da chamada Teoria Mimética, que surge a partir de
obras literárias que mostram relações interpessoais miméticas. Mais tarde, a teoria
é aplicada para entender a violência em sociedades primitivas e contemporâneas.
4. Definição sobre mimetismo trazida por MARTINS, Daniel et al. . Mimetismo com ênfase em espécies vegetais. IN: INTEGRAÇÃO - Revista de ensino, pesquisa e extensão da USJT. n.36. São Paulo: USJT, 2006. pp. 27-31. Definições sobre espécies-modelo e espécies-miméticas oriundas de BUFFALOE, Neal. Diversidade de plantas e animais. São Paulo: Edgar Blucher, 1974 
ser - ao menos momentaneamente - ambígua, tal como ONOS e JODI já citados, camuflando-se e confundindo-se com equivalentes "verdadeiros" ou não artísticos.

Nessa perspectiva, esta pesquisa - em desenvolvimento desde 2012 - já mapeou diferentes produções e tem refletido sobre a natureza das proposições miméticas em arte tecnológica. Ainda que as incursões tecnológicas se favoreçam de um estado de midiatização, já que os novos meios se estabelecem enquanto mediadores sociais de nossas experiências cotidianas (SODRÉ, 2006), percebe-se que a compreensão deste fenômeno não se restringe exatamente às obras de matriz tecnológica, mas sim se estendem para uma gama de criações que flertam com uma condição sistêmica - são obras de arte concebidas para acontecerem sob um determinado ecossistema.

Pode-se dizer que toda criação mimética é também uma incursão na metalinguagem do meio/sistema em questão. Essa criação depende da assimilação daquilo que é regra em seu contexto, assumindo uma aparência ou comportamento que a faz passar veladamente, ao menos momentaneamente. Toma-se de assalto uma audiência desatenta, desvelando sua real natureza e permitindo questionar diretamente nosso poder individual de discernir sobre o "verdadeiro" e o "falso". Quando se descobre o caráter mimético de uma ação artística, há uma nova atenção em jogo. Não por acaso, estas proposições trazem à tona situações características das poéticas conceituais: lança uma quebra de expectativas arraigadas e cria, muitas vezes, um desconforto intelectual ${ }^{5}$.

\section{Mimetismo e o sistema das artes visuais}

Uma abordagem possível dos fenômenos artísticos contemporâneos é entender que toda produção não está limitada a artista e público, mas sim a um conjunto de forças que abrigam as criações em um âmbito social. Nas últimas décadas surge uma nova abordagem social das artes plásticas, que se relaciona com a generalização do processo de mercantilização dos objetos e eventos artísticos - as artes dentro da sociedade de consumo (BULHÕES, 1991, p. 27) - e ao mesmo as necessidades de criar consensos diante de todo um universo de discursos, linguagens e estilos para legitimar o que é ou não arte, como bem explica Maria Amélia Bulhões (idem): "somente o diálogo constante entre artistas, críticos e outros participantes do ambiente artístico tem conseguido ratificar regularmente critérios de julgamento". Disso nascem condições propícias para um sistema de relações que é responsável por produzir, circular e consumir arte. Podemos definir por sistema das artes:

Conjunto de indivíduos e instituições responsáveis pela produção, difusão e consumo de objetos e eventos por eles mesmos rotulados como artísticos e responsáveis também pela definição dos padrões e limites da 'arte' de toda uma sociedade, ao longo de um período histórico. (BOURDIEU e BECKER apud BULHÕES, 1991, p. 29)

\footnotetext{
5. Apontando os conteúdos programáticos comuns da Arte Conceitual (a histórica - produzida entre 1960 e 1970) e das poéticas de conceitualismos, $\operatorname{FREIRE~(1999,~}$ p.29) discorre sobre os elementos presentes:

"A existência da aura (ou sua ausência), o significado do contexto (no caso a exposição elou museu) assim como o papel reservado ao artista se formulam em novas bases nessas poéticas conceituais. A obra Conceitual quebra expectativas
}

arraigadas e cria, muitas vezes, um desconforto intelectual ou em alguns casos, até mesmo físico para o espectador. Frequentemente, a participação a que nos referimos é a atividade resultante desse incômodo. De qualquer maneira, seja através de intervenções no ambiente, (dando a ver o contexto), seja através de projetos envolvendo a consciência do corpo, ou seja, ainda nos trabalhos envolvendo palavras (...) o que importa ressaltar é o predomínio da ideia sobre o objeto". 
Nesta definição, estão incluídos os mais diferentes atores: o mercado das artes, os museus, o público, os agentes culturais, os agentes públicos da cultura, os curadores, os cenógrafos, o jornalismo cultural, os críticos, os especialistas, os próprios artistas e toda gama de indivíduos e instituições envolvidos com artes. Cabe observar que, além de estarmos diante de um complexo com diferentes elementos em interação - o que o caracteriza como sistema como já anteriormente dito -, temos um ponto de convergência que é totalmente dinâmico, visto que a própria definição de arte está sujeita a uma série de articulações que vão muito além da própria obra de arte ${ }^{6}$.

Dada a sua complexidade, o sistema das artes pode ser um ecossistema bastante propício para ações miméticas. Esta perspectiva é trazida por Orson Welles no filme $F$ for fake", no qual nos apresenta aquele que seria "o maior falsificador de arte do século XX", o pintor húngaro Elmyr de Hory. Seu documentário, tão falso quanto os próprios feitos de Hory, indiretamente questiona as instituições que validam o que é ou não arte - em dado momento, diante de uma suposta falsificação: "Isto é apenas uma cópia, meu amigo? Não é também uma pintura?" Ou seja, vale mais o que é legitimado ou o que é transmitido na arte? Muito mais recentemente, o sistema das artes é também questionado no controverso Exit thought the gift shop ${ }^{8}$, documentário de veracidade duvidosa ${ }^{9}$ dirigido pelo street artist Bansky, que conta a história de Thierry Guetta, ou melhor, Mister BrainWash - artista que teria conseguido em apenas um ano ser rico e mundialmente conhecido - discutindo literalmente (e metaforicamente) valores da arte contemporânea.

Seguimos então para as obras propriamente produzidas no âmbito das artes contemporâneas: uma incursão emblematicamente mimética é o trabalho do artista brasileiro Marcius Galan na mostra Planos de Fuga, uma exposição em obras, acontecida no final de 2012 no Centro Cultural Banco do Brasil em São Paulo. O artista, dentro da proposta de trabalhos pensados especialmente para o espaço expositivo, reconfigura vários espaços do CCBB a partir de réplicas cenográficas praticamente idênticas de elementos funcionais - tais como elevadores, extintores, quadros de energia e portas de acesso a serviços. Visitantes desatentos não perceberam, em uma primeira vista, pequenos desvios - como a coluna encalacrada bem na porta de um dos elevadores fakes ou a falta de alguns detalhes nas reproduções. Galan cria um interessante jogo de reconhecimento para o visitante que coloca a sua própria atenção em xeque diante dos itens não artísticos do espaço expositivo, subvertendo a invisibilidade que se atribui a estes itens diante das obras ali expostas.

Pensando o museu institucionalmente, o artista escocês Peter Hill - que cunhou o termo "superficções" para definir incursões artísticas com premissas ficcionais que extrapolam os limites usuais entre ficção e realidade (HILL, 2000) - em 1989 resolveu criar um

\footnotetext{
6. BULHÕES (1991, p. 29), sobre o conceito de sistema das artes: "Este conceito apresenta um caráter dinâmico e totalizante. Dinâmico, porque concebe seu objeto como um conjunto em movimento; totalizante, pois o vê como resultado de um conjunto de articulações internas e externas à própria obra de arte".

7. F for fake (no Brasil: Verdades e Mentiras). França-Irã-Alemanha, 1973. Um dado interessante é que Orson Welles em $F$ for Fake relembra que ele mesmo assim como o falsificador Elmyr apresentado no filme - enganou audiências com a sua transmissão de A Guerra dos Mundos em 1938, que, narrada com todos os elementos noticiosos típicos do rádio, causou enorme pânico aos ouvintes que imaginavam uma invasão alienígena real.
}

8. Exit thought the gift shop. Estados Unidos, Reino Unido, 2010.

9. Há especulações de que a história contada sobre Mr. BrainWash seja uma farsa. Críticos apontam que muitas situações são muito artificiais - e engraçadas demais - para serem reais. Há aqueles que apontam que o próprio Mr. BrainWash poderia ser na verdade Bansky - artista que a apesar de sua fama, até o momento, nunca relevou sua verdadeira identidade. De qualquer modo, Bansky nunca assumiu o documentário como falso e, por sua vez, o protagonista Thierry Guetta (mesmo depois do filme) continua realizando suas produções. 
museu fictício sediado em Nova York chamado de Museu de Ideias Contemporâneas que, inicialmente, existia apenas por meio de sua assessoria de imprensa. Ao conceber o projeto, o artista optou por enviar comunicados de imprensa - press releases ${ }^{10}$ - para agências de notícias como Reuters e Associated Press, bem como para galerias de arte, diretores de museus, editores de revistas e alguns amigos, descrevendo o trabalho como supostamente "o maior espaço do mundo contemporâneo para explorar arte e ideias".

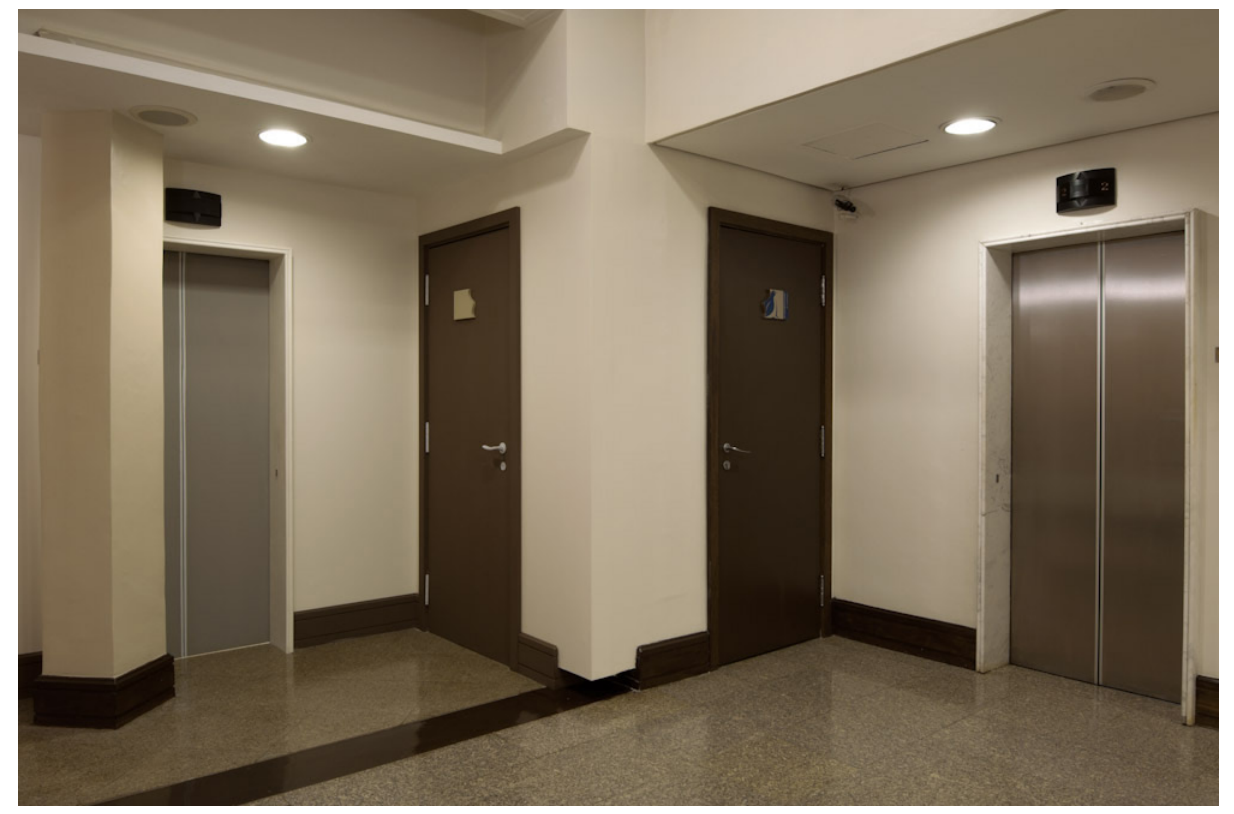

Figura 1: Uma das intervenções de Marcius Galan no CCBB-SP, em 2012. Fonte: Site pessoal do artista. Disponível em: http://marcius-trabaIhos.blogspot.com.br/. Acesso em 20.05.2014.

Também fazendo uso de uma assessoria de imprensa, o artista brasileiro Yuri Firmeza realizou no final de 2005 uma interessante ação artística na cidade de Fortaleza. Assim como outras incursões miméticas, Firmeza faz uso de uma persona - assumindo um personagem de um dado contexto. Esta prática proporciona um estado de "despersonalização" - para usar um termo recorrente para definir os heterônimos de Fernando Pessoa (FABRIS, 2012, p. 80) - desvinculando-se da personalidade do artista e emulando uma nova. Então Firmeza cria a figura fictícia de Souzousareta Geijutsuka ("artista inventado" em japonês, segundo o artista), que seria um notório criador em arte e tecnologia no Japão prestes a expor trabalhos no Museu de Arte Contemporânea da capital cearense. Em acordo com a direção do museu para a sua ação, Firmeza passa a estabelecer contato com jornais locais a partir de uma assessoria de imprensa, enviando press releases; ninguém questiona o fato de não existir uma linha sequer sobre o artista japonês na rede Internet ou a aparente banalidade das fotos de supostos trabalhos, como uma paisagem qualquer retocada em um editor de imagens e uma prosaica imagem de um gato. Assim, notícias sobre a exposição ocupam espaços nobres da imprensa local, até que no momento da suposta abertura do evento, a farsa é descoberta. Não há obras, nem artista.

\footnotetext{
10. Press release é um comunicado para a imprensa - um texto de individuo ou instituição - com o propósito de divulgar um fato, podendo ser base para um texto noticioso.
} 
Diante do esclarecimento de tudo, segue-se uma reação indignada e violenta da mídia local, sendo esta "uma alavanca para o projeto que ganhou notoriedade e atenção da imprensa nacional, criando um debate inédito sobre o uso de mídia e sua relação com a arte contemporânea" (PELED, 2012, p. 58). Souzousareta explicita a fragilidade da imprensa, que pode imprimir relevância cegamente - sem checar a veracidade dos fatos - sobretudo ao que é estrangeiro.

Já Bruno Moreschi, outro autor brasileiro, realizou uma enciclopédia de arte com 50 (cinquenta) artistas ficcionais concebidos por ele. O projeto de Moreschi chama-se ART $B O O K$ e foi lançado como livro tal como as demais enciclopédias de arte contemporânea de títulos conhecidos mundo afora. Inicialmente, Moreschi pesquisou e enumerou 60 (sessenta) modelos de artistas contemporâneos ou "tipos de artista", tal como "artista chinês que seus trabalhos sejam interpretados como a condição atual da China", "artista que critica o mundo da moda e do consumo" ou ainda, "artista palestino ou iraniano que faz arte sobre sua condição exclusão no mundo" (MORESCHI, 2014, p. 63-67). Isso feito, elegeu 50 (cinquenta) destes tipos e passou - ele próprio - a desenvolver cada uma das 311 obras a serem fotografadas, resenhadas e analisadas na enciclopédia, em variadas linguagens, como desenho, fotografia, performance, videoarte e pintura, e mesmo dentre estas, os mais diferentes estilos - do desenho intimista a projeções urbanas megalomaníacas.
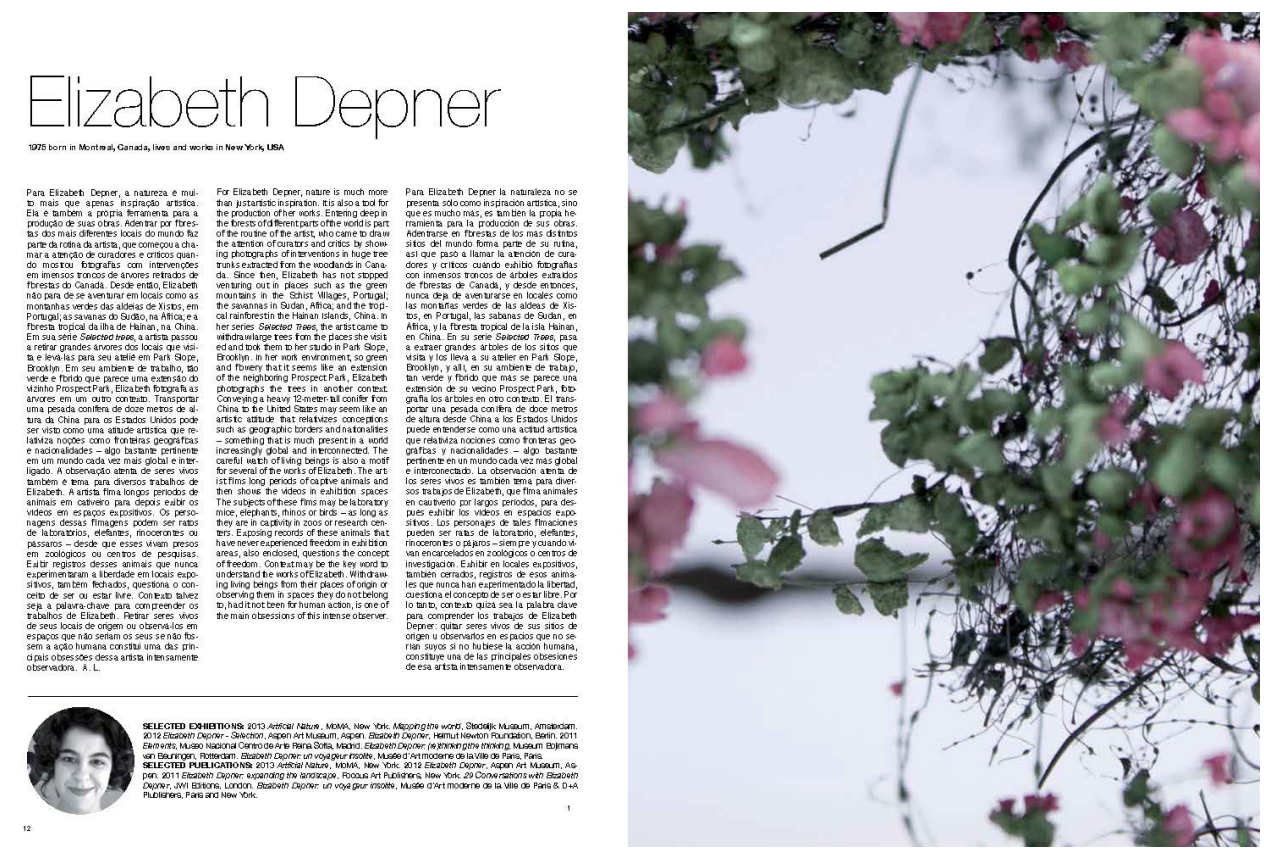

Figura 2: Páginas da enciclopédia ART BOOK (2013) de Bruno Moreschi. Fonte: MORESCHI, B. (org.). ART BOOK - 50 artistas contemporâneos. São Paulo: P. Menard Editions, 2013.

Essa disparidade entre as obras suscita a percepção de que estamos diante de um compêndio efetivo de nomes que compõem o eclético mundo contemporâneo das artes. Naturalmente que essa percepção contribui para a camuflagem do caráter ficcional da publicação, além, é claro, da mimetização do formato "enciclopédia de arte": textos curtos, apresentação em inglês e outras línguas, bibliografias de artistas com fotos, imagens bem trabalhadas das obras, tudo produzido seguindo procedimentos típicos do tipo de publicação a ser mimetizada. Para completar, Moreschi 
convidou jornalistas, críticos e outros especialistas em artes visuais para que realizassem textos críticos a serem publicados ao final do livro. Os autores dos textos poderiam escrever o que bem quisessem, desde que não relevassem o caráter ficcional de forma direta. Aliás, em nenhum momento o livro releva diretamente que nenhum daqueles artistas de fato existe. O livro foi doado a dezenas de bibliotecas especializadas em artes visuais, e contou com recursos da FUNARTE ${ }^{11}$ em sua realização.

O projeto evidencia a enciclopédia de arte como um espaço de legitimação, criticando o caráter dúbio e superficial de escolhas e abordagem desse tipo de publicação ${ }^{12}$, muitas vezes a reboque do próprio mercado de arte. Além de ser naturalmente um projeto inscrito dentro da seara conceitualista, tal como todas as incursões miméticas aqui descritas, em sua dissertação de mestrado voltada para a análise de seu trabalho prático, o autor nota que o projeto "precisa de um ecossistema para de fato existir" (MORESCHI, 2014, p.07). Essa necessidade contextual é parte fundamental para se entender os trabalhos que fazem uso de estratégias miméticas, reforçando o que trouxemos até aqui.

\section{Incursões tecnológicas}

As proposições miméticas em torno do sistema das artes naturalmente se estenderão aos trabalhos que fazem uso de matrizes tecnológicas. Talvez por ainda trafegar em alguns circuitos diferentes daqueles nos quais se apresentam as criações não tecnológicas, constituindo-se em um domínio muitas vezes paralelo onde há críticos, programas de fomento, espaços expositivos ou especialistas específicos, ou ainda um mercado bastante incipiente, a arte das novos meios carrega consigo inevitavelmente um olhar destoante sobre alguns dos elementos deste complexo e por extensão, sobre a própria "concepção de arte".

Nesse sentido, as estratégias miméticas para a discussão do sistema das artes muitas vezes lançam mão de repensar aquele que seria uma das partes dissociáveis deste complexo: a figura do artista. É recorrente, desde o século passado, a ideia de mimetizar a ação plástica do artista: um dos nomes mais significativos neste sentido é o suiço Jean Tinguely, conhecido por suas máquinas que satirizam o otimismo tecnológico e científico do pós-guerra no século $\mathrm{XX}$, criando máquinas que imitam o gesto espontâneo do expressionismo abstrato como em Metamatics (1955-1959).

Com as tecnologias digitais, temos vários exemplos bastante significativos, como os robôs do grupo alemão Robotlab, que realizam com grande perfeição imagens figurativas, como na obra Autoportrait (2002), onde o autômato é capaz de realizar retratos humanos de seus visitantes manipulando habilmente uma caneta diante dos próprios retratados. Ou ainda os robôs-artistas do artista português Leonel Moura, que defende o surgimento de um "artista simbiótico", um novo paradigma para o artista contemporâneo, que deixaria de

11. FUNARTE: Fundação Nacional das Artes, instituição vinculada ao Ministério da Cultura brasileiro.

12. Sobre a forma da enciclopédia de arte, MORESCHI (2014, p. 11): "Seu pertencimento na historiografia da arte é dúbio e problemático. Não são livros de História da Arte, mas também não são propriamente porttólios de artistas ou peças publicitárias de galerias e museus. Uma miscelânea esquizofrênica as define. De um lado, o efeito de uma autoridade parcial é produzido com base em uma espécie de roupagem pseudocrítica que vende ao leitor a imagem de uma seleção primorosa de artistas (sempre em números redondos: 25, 50, 100 ) e repleta de supostos critérios (mas nunca apresentados de fato, afinal, esses critérios, se existirem, são do mercado de arte e não da crítica). Há também uma espécie de agilidade típica de uma propaganda: um conjunto de textos de fácil leitura ao lado de centenas de imagens coloridas". 
produzir diretamente produtos artísticos para criar agentes artificiais devotados às artes (MOURA e PEREIRA, 2004) - ou seja, em vez de realizar diretamente objetos artísticos, criar artistas. Os robôs de Moura possuem habilidade de criar imagens gráficas e pictóricas - intencionalmente confundíveis com obras criadas diretamente por mãos humanas.

Nesse contexto, a presente pesquisa tem desenvolvido uma persona de um "artista tecnológico" exageradamente irônico e provocativo, além de extravagante e com trabalhos que muitas vezes pecam pelo excesso. Uma amostra de sua produção são as várias séries de trabalhos de net art disponíveis por meio de seu site pessoal, que se constituem em sequências de imagens sobrepostas, assemblages com pouco rigor estético. Neste site há também referências de outras obras já realizadas e outras informações. Mas a obra mais significativa de Mimo Steim será sua teleperformance $O$ artista estah tele presente $(2013)^{13}$, quando resolve eliminar todas as suas relações que não sejam mediadas pelo ciberespaço. A intenção desta teleperformance seria imergir em um estado máximo de midiatização de suas relações. Para tanto, o artista teria se isolado em um espaço desconhecido e por tempo indeterminado, tendo contato com outras pessoas somente através de ferramentas de relacionamento do ciberespaço, tais como as redes sociais, mas, prioritariamente através de seu próprio site (www.mimosteim.me), no qual possui uma sala de bate-papo aberta ininterruptamente.

As relações estabelecidas por Mimo Steim via bate-papo em rede estão pautadas pelo seu caráter provocativo: tenta conduzir seu interlocutor ora por incessantes e intrincadas perguntas, ora por relativizar a importância do visitante diante da sua suposta genialidade. Cabe esclarecer, na verdade, que o interlocutor de Mimo Steim se relaciona com um sistema baseado em Linguagem de Marcação de Inteligência Artificial (AIML) - um chatbot ou robô de conversação - capaz de simular uma conversa, como as estabelecidas entre seres humanos. Os chatbots (ou ainda, chatterbots) são bastante comuns na rede Internet para fins educacionais, comerciais ou mesmo, de entretenimento, como um "amigo virtual".

A definição de Mimo Steim como "artista tecnológico" não é, portanto, uma definição de sua vertente de criação, mas sim de sua própria essência enquanto agente tecnológico. Em suas conversas, não se referenciará somente a ser artista, mas a ser ele próprio - arte. Mimo é um artista mimético que não só assume uma persona, mas que mimetiza um quase discurso de artista, através de suas quase 5.000 (cinco mil) sentenças carregadas de questionamentos artísticos, conceituais e pessoais, além de momentos de embates excêntricos com seus interlocutores. Mimo Steim questiona a expectativa do encontro entre público e artista, especialmente da visão do artista como senhor de uma situação dada e como entidade romantizada - e por consequência, inacessível. No entremeio desta condição está a constatação de que as redes digitais permitem contornar a imprescindibilidade do museu como espaço deste encontro.

13. O título é uma homenagem irônica a Marina Abramović e sua performance $A$ artista está presente, apresentada em 2012 no Museu de Arte Moderna de Nova York. Neste trabalho a conhecida artista dividiu, por dois meses, alguns minutos do seu olhar fixo com completos estranhos que se dispuseram a sentar à sua frente, um a um. A encarar cada um, Marina estabelece um silencioso diálogo como cada participante - que pode ir da euforia de ser o centro de atenções da artista ao constrangimento de ser ininterruptamente observado. Em ambas as circunstâncias, Marina e Mimo estabelecem "recebem" desconhecidos, colocando-se à disposição. 


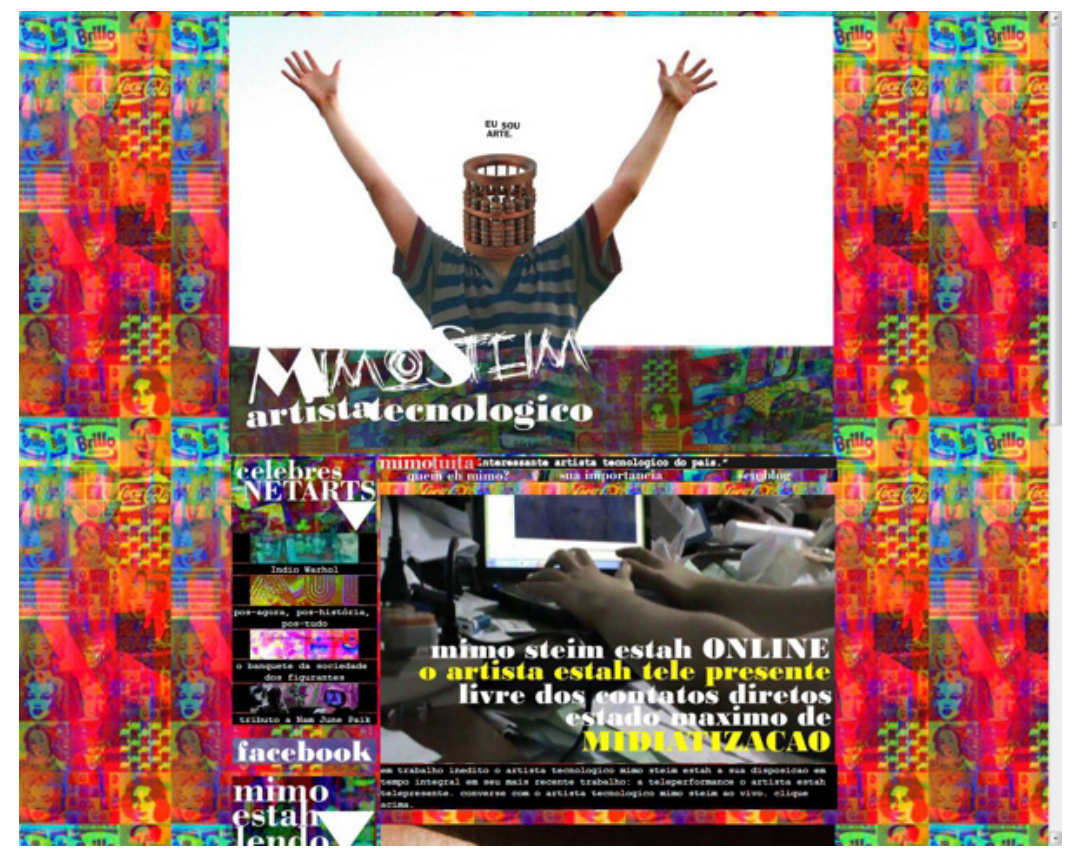

Figura 3: Página de abertura do site de Mimo Steim. Fonte: Site pessoal do artista. Disponível em http://www.mimosteim.me. Acesso em 30.05.2014.

\section{Algumas considerações}

É interessante pensar o que pode representar estes jogos miméticos para a arte e seus artistas. Bulhões (1991, p. 30) nos diz que o sistema das artes surge também como um "sistema de dominação", na medida em que seus integrantes impõem padrões que eram de uma minoria. É notório que o sistema das artes atribui uma hierarquização sobre o que é mais ou menos relevante - visto que nem toda criação plástica ou visual aqui se enquadra: como bem sabemos, há distinções entre "arte" e "artesanato", por exemplo. Essa distinção não só busca legitimar as convenções do sistema como também oferece distinção aos que dele participam ou desfrutam, numa forma de poder político mascarado:

Essa forma de poder mascara-se através da crença na magia do criador e na individualidade autônoma das produções; crença na sabedoria despolitizada dos críticos e na devoção abnegada dos consumidores (idem).

De alguma forma, os artistas que questionam o sistema das artes (ainda que o façam no interior daquilo que indagam) podem semear novos olhares para estruturas tão cristalizadas. Como bem pontua Nicolas Bourriaud (2009, p. 86), "a imitação pode ser subversiva, muito mais do que certos discursos de oposição frontal que apenas encenam gestos de subversão". Para o autor, ao analisar a produção em arte contemporânea, é necessário assumir ou pelo menos envergar a forma daquilo que se quer criticar.

Em uma experiência mimética - ao desconhecer o caráter ficcional destas ações abordadas - recobra-se um olhar menos viciado sobre as estruturas, pois é justamente a partir destas que a camuflagem em questão se constrói. Reconsideraremos, então, 0 modelo a partir de sua cópia desfigurada - o tratamento da imprensa sobre os artistas, o 
formato das enciclopédias de arte contemporânea ou a figura deificada do artista, para citar algumas das situações que já abordamos neste breve percurso. Em todos os casos, ao mobilizar novas atenções, é notório o poder reflexivo das ações miméticas.

\section{Agradecimentos}

O autor agradece ao apoio da FAPESP - Fundação de Amparo à Pesquisa do Estado de São Paulo na realização deste trabalho. 


\section{Referências}

BOURRIAUD, N. Pós-produção. São Paulo: Martins, 2009.

BULHÕES, M. A. Considerações sobre o Sistema das Artes Plásticas. In: PORTO ARTE, Porto Alegre, v.2, n.3, maio 1991.

SODRÉ, M. Eticidade, campo comunicacional e midiatização. In: MORAES, D. (org.). Sociedade Midiatizada. Rio de Janeiro: Mauad, 2006. p. 19-31.

DONATI, L. A. P. Análise Semiótica do Site Jodi. In: REVISTA DA PÓS GRADUAÇÃO, Instituto de Artes, Unicamp, Campinas, vol.1, n.2, pp.103-111, 1997.

FABRIS, A. Os heterônimos de Dora Longo Bahia ou os dilemas do sistema de arte. In: POÉTICAS VISUAIS - Revista do Programa de Pós-Graduação em Poéticas Visuais da Faculdade de Arquitetura, Artes e Comunicação da UNESP. Bauru: FAAC-UNESP, 1요 semestre, 2012. pp. 79-88.

FREIRE, C. Poéticas do Processo - Arte conceitual no museu. São Paulo: lluminuras/ MAC-USP, 1999.

GEBAUER, G.; WULF, C.. Mimese na cultura: Agir social, rituais e jogos, produções estéticas. São Paulo: Annablume, 2004.

HILL, P. Superfictions: the creation of fictional situations in international contemporary art practice. Tese (Doctor of Philosophy). Melbourne University - RMIT. Melbourne, 2000.

MORESCHI, B. ART BOOK: A construção de uma enciclopédia de artistas. 2014. 76 p. Dissertação (mestrado em artes) - Programa de Pós-Graduação em Artes Visuais, Universidade Estadual de Campinas, Campinas, 2014.

MOURA, L.; PEREIRA, H. G.. Symbiotic Art Manifesto. [Sl.: s.n., 2004]. Disponível em http://www.leonelmoura.com/manifesto.html. Acesso em 10.05.2014.

NUNES, F. O. CTRL+ART+DEL: Distúrbios em Arte e Tecnologia. São Paulo: Perspectiva, 2010.

PELED, Y. Performance na contemporaneidade. ARS (São Paulo) vol. 10 n. 19, São Paulo, 2012. pp. 48-63. Disponível em: http://www.scielo.br/pdf/ars/v10n19/a05v10n19. pdf. Acesso em 15.05.2014. 
SANTOS, N. C.; TELLES NETO, H. O Processo sistêmico e interdisciplinar na arte: Entremeios II/SCIARTs. In: MARTINS, M. V. G.; HERNÁNDEZ, M. H. O. (Org.). Anais do 19을 Encontro Nacional da ANPAP. Cachoeira, BA: ANPAP/EDUFBA, 2010.

\section{Autor}

\section{Fabio Oliveira Nunes}

Doutor em Artes

Instituto de Artes da Universidade Estadual Paulista - UNESP

São Paulo, São Paulo, Brasil

fabiofonagmail.com 